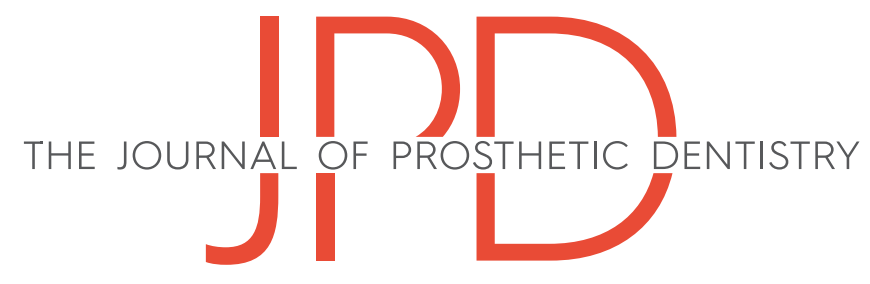

CLINICAL REPORT

\title{
Single-stage osseointegrated implants for nasal prosthodontic @ rehabilitation: A clinical report
}

\author{
Bruna M. D. F. de Carvalho, MSD, ${ }^{a}$ Karina M. Freitas-Pontes, $\mathrm{PhD}^{\mathrm{b}}$ Wagner $\mathrm{A}$. de Negreiros, $\mathrm{PhD}^{\mathrm{c}}$ and \\ Marcus A. R. L. Verde, $\mathrm{PhD}^{\mathrm{d}}$
}

A considerable number of people are affected by facial defects every year as a result of malignant tumors, trauma, or congenital deformities. Malignant skin neoplasms in the head and neck region are common in places where there is intense sunlight all the year around. In Brazil, among head and neck lesions, the incidence of nasal tumors is $31.5 \% .{ }^{1}$ The majority of these tumors are basal cell carcinoma, ${ }^{1}$ and if they are not diagnosed early and treated, they may be fatal. ${ }^{2,3}$ Cancer treatment in the nasal region usually involves surgery, either associated with radiotherapy and/or chemotherapy or neither..$^{3-5}$

As a result of surgery, disabling facial defects are common in these patients, who will require follow-up appointments and rehabilitation procedures throughout their lives. Rehabilitation may be performed through plastic surgery or a nasal prosthesis. ${ }^{4,6,7}$ The choice of treatment depends on the size, site, etiology, and severity of the neoplasm, the patient's age, and availability. However, age, general clinical status, type and intensity of radiation therapy, morphologic or surgical complexity, and recurrence of disease affect the appearance of the rehabilitation area. Moreover, a patient's refusal to undergo surgery may lead to large residual lesions., ${ }^{3,5}$ In these patients, prosthetic rehabilitation will offer various advantages, including inspection of the surgical site, early diagnosis of disease recurrence, good esthetics, simplicity of technique, and lower cost. ${ }^{6}$

Successful maxillofacial prostheses may be evaluated by considering esthetics, functional performance, biocompatibility, durability, and retention without compromising skin integrity, even right after surgery when a provisional prosthesis is recommended. ${ }^{8}$ Mechanical retention and adhesives have shown poor results as means of retention and will reduce prosthesis durability. ${ }^{9}$

Retention and anchorage provided by extraoral implants is the best method of support for facial prostheses. ${ }^{10,11}$ However, before performing the rehabilitation, meticulous reverse planning based on a diagnostic waxing of the future prosthesis is necessary. Extraoral implants must be ideally positioned to guarantee satisfactory prosthesis volume and contour. ${ }^{12-14}$ Adequate laboratory processing and silicone color selection are also important to achieve successful treatment outcomes. ${ }^{15}$ A method of prosthetic retention with the use of single-stage implants

\footnotetext{
a Postgraduate student, Federal University of Ceará, Federal University of Ceará, School of Pharmacy, Dentistry and Nursing, Fortaleza, Brazil.

${ }^{\mathrm{b}}$ Associate Professor, Department of Restorative Dentistry, Federal University of Ceará, School of Pharmacy, Dentistry and Nursing, Fortaleza, Brazil.

${ }^{\mathrm{C}}$ Associate Professor, Department of Restorative Dentistry, Federal University of Ceará, School of Pharmacy, Dentistry and Nursing, Fortaleza, Brazil.

${ }^{d}$ Associate Professor, Department of Restorative Dentistry, Federal University of Ceará, School of Pharmacy, Dentistry and Nursing, Fortaleza, Brazil.
} 


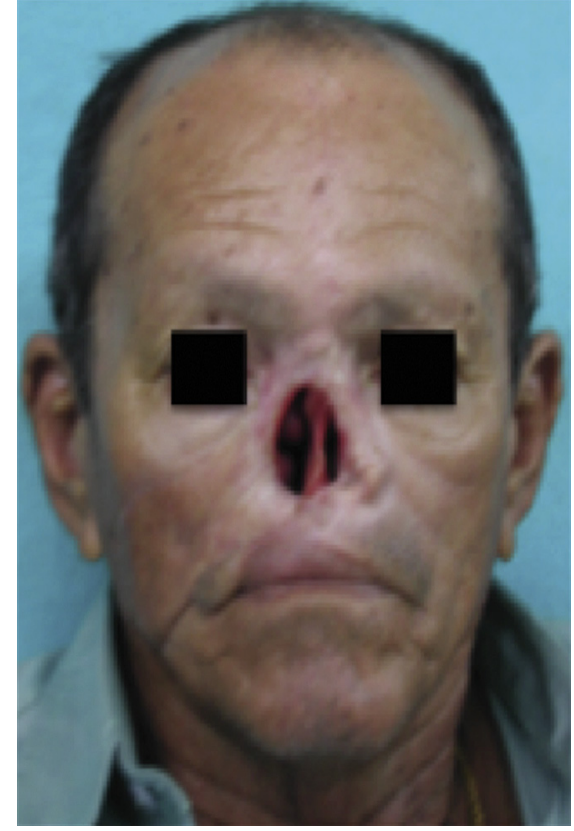

Figure 1. Preoperative appearance.

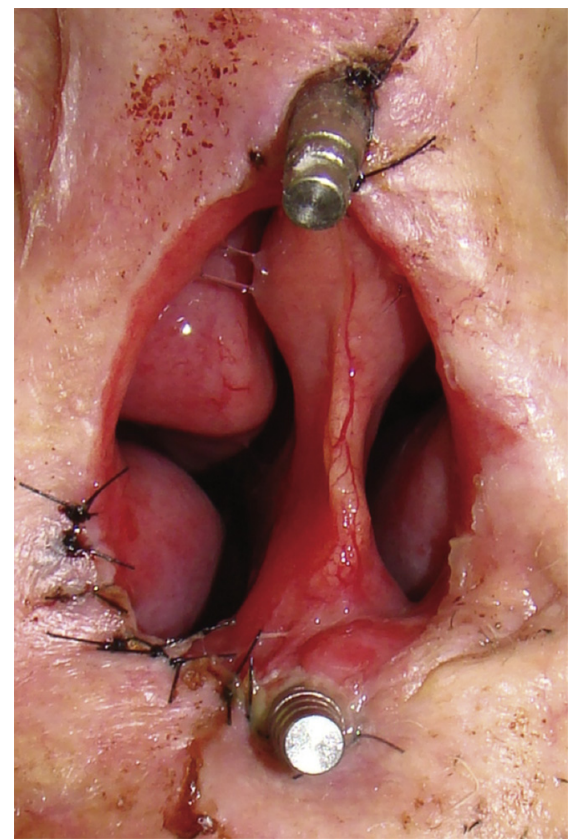

Figure 3. Standard abutments and conical impression transfers to prevent soft tissue closure.

and magnets is described for a patient who underwent a total rhinectomy because of a basal cell carcinoma in the nasal vestibule.

\section{CLINICAL REPORT}

A 75-year-old, fair-skinned man who had undergone a rhinectomy because of a basal cell carcinoma and who had been using an adhesive-retained nasal prosthesis

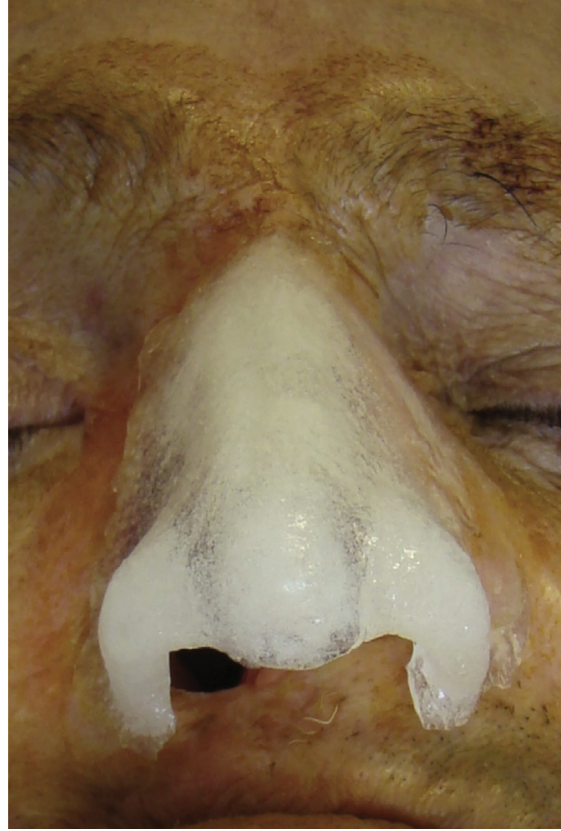

Figure 2. Implant surgical guide in place.

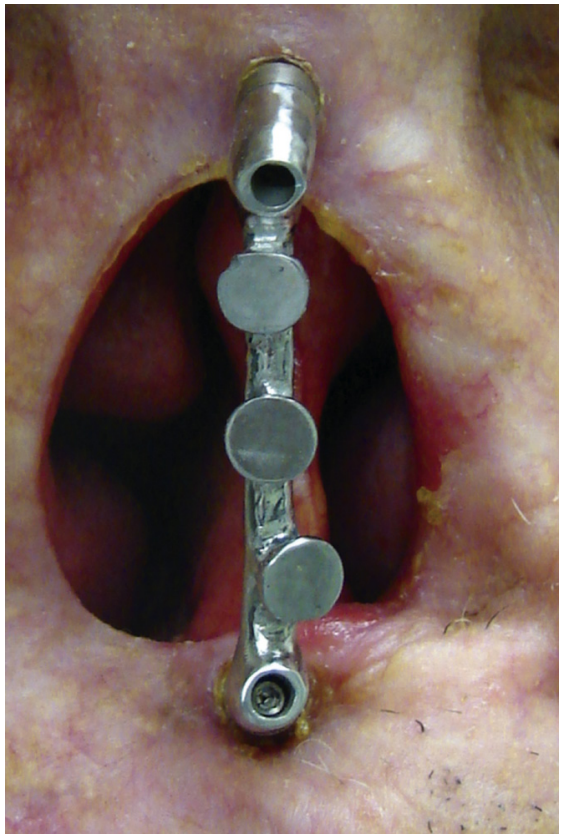

Figure 4. Appointment for seating metal bar with magnet inserts.

(Fig. 1) was referred to the NUFACE clinic (Facial Defects Rehabilitation Clinic) at the Federal University of Ceará, Brazil, with regard to the possibility of nasal reconstruction. Different treatment approaches were presented to the patient and his relatives. The approved treatment plan involved an implant-retained, removable silicone nose. The patient also reported hiding from people, mostly because of the residual lesion after the rhinectomy. A surgical guide (Fig. 2) was used to indicate 


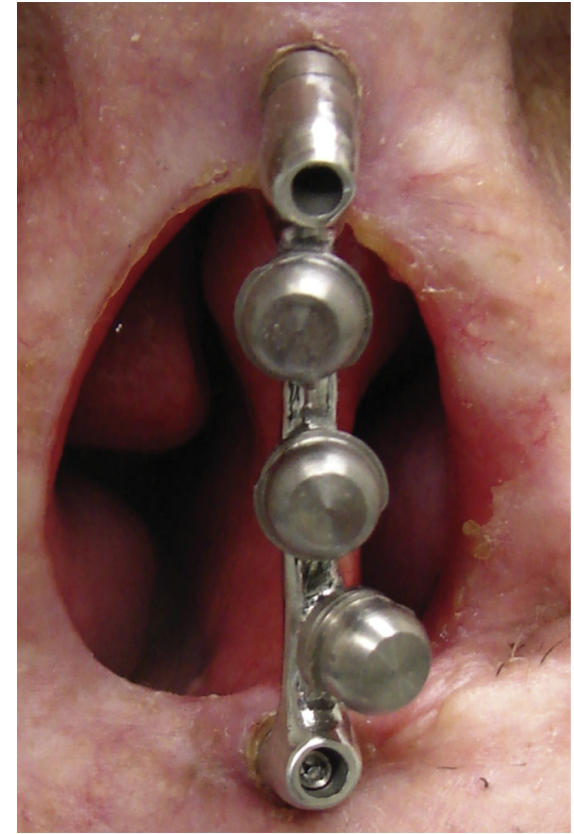

Figure 5. Magnets positioned on top of magnet inserts.

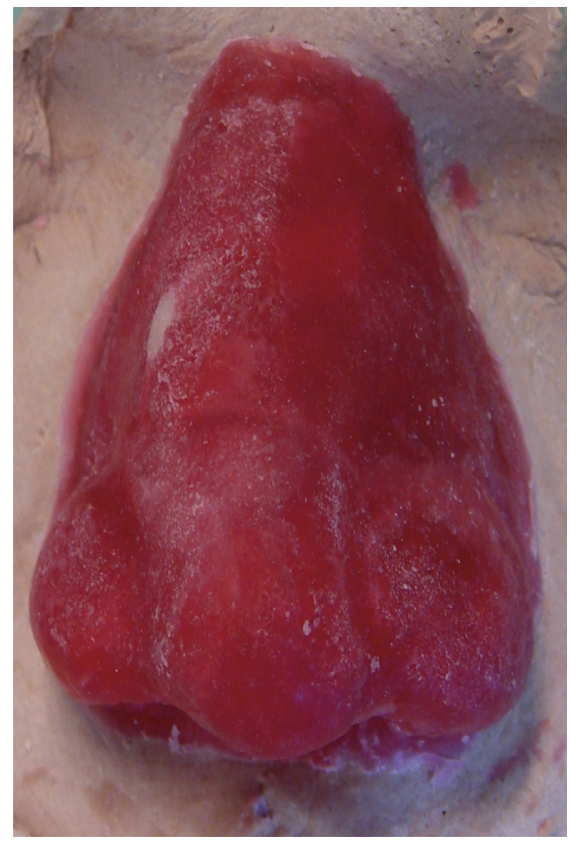

Figure 7. Definitive model and nose waxing.

the optimal implant position. Two $3.75 \times 13-\mathrm{mm}$ dental implants (Master Porous; Conexão Sistemas de Prótese) were placed in the nasal spine and areas of the glabellae. Standard abutments (Conexão Sistemas de Prótese) were screwed on the implants, and conical impression posts (Conexão Sistemas de Prótese) were placed on the standard abutments. Sutures were made arranging the skin tissue around the abutments, which remained exposed (Fig. 3). Two weeks later, the sutures were

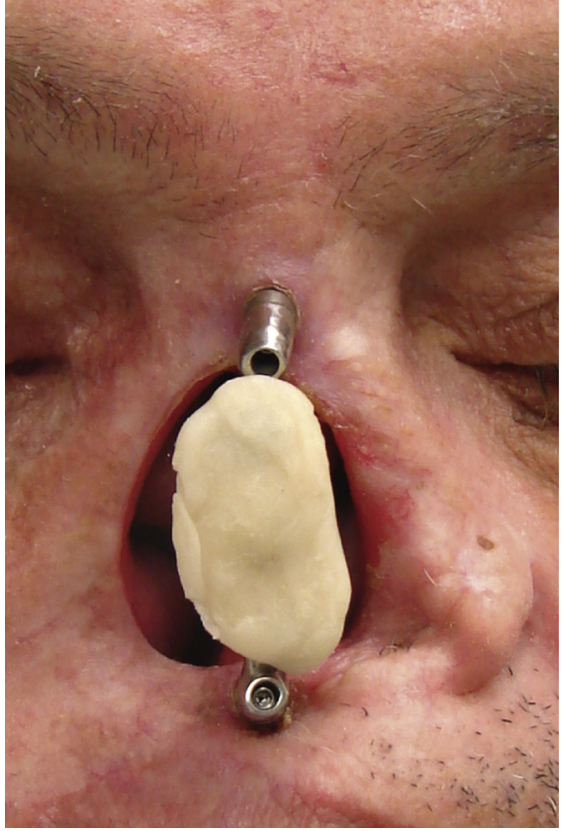

Figure 6. Magnet and acrylic resin stent to provide nose retention.

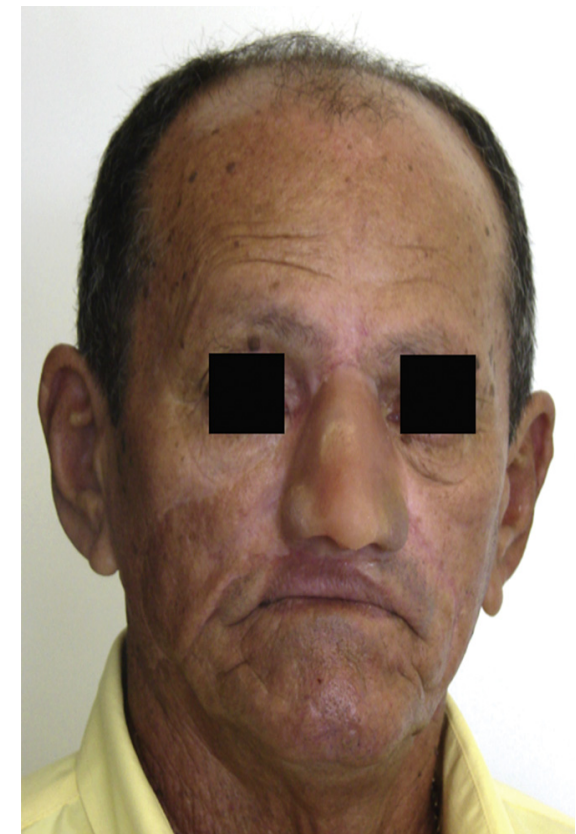

Figure 8. Definitive prosthesis insertion appointment.

removed, and definitive impressions were made with a polyvinyl siloxane material (Adsil; Coltène/Whaledent). Standard abutment analogs (Conexão Sistemas de Prótese) were screwed on the impression transfers and the impression was poured in Type IV stone (Durone; Dentsply Intl). Three lip magnet inserts (IK2-S; Technovent) (Fig. 4) were used to make a Co-Cr alloy bar (Fig. 5) (Starlloy; Degussa). After the bar-seating appointment, an acrylic resin (Fig. 6) stent containing 3 
magnets (ML3-S; Technovent) was fabricated, and a nose was waxed over it. The waxed nose (Fig. 7) was then flasked (\#6 flask; DCL). The wax was eliminated and a fine layer of separating medium (Al-Cote; Dentsply Intl) was applied to the stone mold. Afterwards, the prosthesis was fabricated from a platinum silicone (MDX4210; Dow Corning) and intrinsically colored with a coloring system (rare earth pigments; Factor II Inc). During the prosthesis insertion appointment, the patient was provided with guidance on cleaning, and maintenance (Fig. 8).

\section{DISCUSSION}

Craniofacial osseointegrated implants offer patients with a facial prosthesis a significantly improved quality of life. ${ }^{10}$ Extraoral implants have many advantages in maxillofacial prosthetic rehabilitation: they provide consistent retention and positioning of the facial prosthesis and can be placed during the primary reconstruction procedure or at any time postoperatively when the patient is able to tolerate the procedure ${ }^{11}$ In addition to predictable retention, the rehabilitation time was reduced, ${ }^{12}$ as a single-stage osseointegrated implant surgery protocol was adapted to the craniofacial region. The patient was instructed to avoid any pressure or premature loading on the surgical area, and all postoperative care was taken because micromovement or infection could have led to implant failure. ${ }^{13}$

The patient did not present any soft tissue problems, which are most commonly related to poor hygiene, physical irritants, and/or excessive thickness and mobility of soft tissues around the implant. Patients with oral malignancies are often treated with surgery followed by radiation therapy. Once irradiated, the potential of the bone for implant placement may be severely compromised or even lost because of the decrease in bone osteogenic potential and microvascularity. Adjunctive therapies such as hyperbaric oxygen and subsequent implant placement in irradiated bone have been proposed to overcome this problem. ${ }^{7}$ In this patient, radiation therapy was not used as a part of the treatment.

The magnetic retention used was a lip magnet that restrains any lateral movement of the prostheses and enhances positioning for elderly or physically impaired patients. One disadvantage is that the cost is slightly higher than bar and clip or ball and keeper systems. It is more difficult to perform the necessary hygiene than with conventional adhesive prosthetic appliances. ${ }^{14}$

In this clinical report, an implant-retained nasal prosthesis was used in a patient who had previously had a conventional nasal prosthesis. In the first follow-up appointment, the patient reported a better relationship between the skin/prosthesis interface, stronger retention, and a better esthetic result, probably because of very thin margins. The reduction in rehabilitation time was mostly related to the single surgical procedure, which not only reduced rehabilitation time but cost as well. This study should be seen as a possible treatment alternative and is suggested by the authors as a way to enhance maxillofacial reconstruction. Survival rates will only be known when the number of patients receiving this treatment increases and the duration of follow-up is extended.

\section{SUMMARY}

A patient who underwent rhinectomy because of a basal cell carcinoma underwent a single-stage endosseous implant surgery. After the surgical procedure, he had nasal rehabilitation through the fabrication of a nasal implant-supported and magnet-retained prosthesis.

\section{REFERENCES}

1. Brazil. Ministry of Health. National Cancer Institute. Estimate 2014: incidence of cancer in Brazil. Available at: http://www.inca.gov.br/estimativa/2014. Accessed November 22, 2014

2. Santos ABO, Vergilius VL, Araújo Filho AF, Ferraz AR. Epidemiologic study of 230 aggressive basal cell carcinomas in head and neck. Rev Bras Cir Head Neck 2007;36:230-3.

3. Ramchandani PL, Flood TR. Rhinectomy for nasal cancer a nine-year experience. J Craniomaxillofac Surg 2002;30:2-6.

4. Bowdena JR, Flood TR, Downie IP. Zygomaticus implants for retention of nasal prostheses after rhinectomy. Br J Oral Maxillofac Surg 2006;44:54-6.

5. Harrison DF. Total rhinectomy- a worthwhile operation. J Laryngol Otol 1992; 96:1113-23.

6. Chang TL, Garrett N, Eleni R, Beumer J. Treatment satisfaction with facial prostheses. J Prosthet Dent 2005:94:275-80.

7. Wathson RFC, Antunes AA, Silva EDO, Neto AL, Loretto NRM. The use of osseointegrated implants for oral and maxillo-facial prosthodontic retention: literature review. Rev Cir Traumatol Buco-Maxilo-fac 2008;8:9-14.

8. Rosen EB, Golden M, Huryn JM. Fabrication of a provisional nasal prosthesis. J Prosthet Dent 2014;112:1308-10.

9. Pattanaik BS, Seema B, Wadkar, Aarti P. Prosthetic rehabilitation of a patient with congenital oro-nasal defect with an interim prosthesis: a case report. J Indian Prosthodont 2011;11:113-8.

10. Abu-Serriah MM, McGowan DA, Moos KF, Bagg J. Outcome of extra-oral craniofacial endosseous implants. Br J Oral Maxillofac Surg 2001;39:269-75.

11. Toljanic JA, Eckert SE, Roumanas E, Beumer J, Huryn JM, Zlotolow IM. Osseointegrated craniofacial implants in the rehabilitation of orbital defects: an update of a retrospective experience in the United States. J Prosthet Dent 2005; $94: 177-82$

12. Wolfaardt J, Gehl G, Farmand M, Wilkes G. Indications and methods of care for aspects of extraoral osseointegration. Int J Oral Maxillofac Surg 2003;32: 124-31.

13. Adell R, Lekholm U, Rockler B, Branemark PI. A 15-year study of osseointegrated implants in the treatment of the edentulous jaw. Int J Oral Surg 1981;10:387-416.

14. Hatamleh MM, Haylock C, Watson J, Watts DC. Maxillofacial prosthetic rehabilitation in the UK: a survey of maxillofacial prosthetist's and technol ogist's attitudes and opinions. Int J Oral Maxillofac Surg 2010;39:1186-92.

15. Negreiros WA, Lima Verde MAR, Silva AM, Pinto LP. Surgical and prosthetic considerations to rehabilitate an ocular defect using extraoral implants: a clinical report. J Prosthodont 2012;21:205-8.

Corresponding author:

Dr Bruna Marjorie Dias Frota de Carvalho

Rua Monsenhor Furtado S/N

Rodolfo Teófilo 60430-350

Fortaleza, CE

BRAZIL

Email: brunafrota@hotmail.com

Acknowledgments

The authors thank Conexão Sistemas de Prótese for the donation of both implants and prosthetic components, making rehabilitation of this patient possible.

Copyright (C) 2015 by the Editorial Council for The Journal of Prosthetic Dentistry. 